Assessment-case reports

Some centres already require their trainees to produce psychotherapy case reports: others might consider following their example. Such reports have the advantage of increasing the relevance and immediacy of psychotherapy training and of impressing more permanently on the trainee the lessons learned. Case reports should describe the case history, relevant theoretical issues, the treatment given, the patient's response to treatment and the outcome. Relevant literature may be discussed. We suggest each trainee write reports, including at least one case each of dynamic, behavioural and supportive psychotherapy. These case reports should be submitted to the supervisor. Consultant psychotherapists and psychiatric tutors in each region should arrange to evaluate the case reports for the benefit of trainees and different forms of assessment might fruitfully evolve.

\title{
Election to the Fellowship
}

Candidates for election to the Fellowship are considered annually by the Court of Electors.

Candidates may not make a personal approach to the College for election, but must be nominated by two sponsors, who must be Fellows of the College.

Sponsors should apply in writing to the Registrar for the relevant forms. Completed nominations should be submitted to the Registrar by 30 September in any year, for consideration by the Court at its meeting the following February.

\section{Eligibility of nominees}

a. Candidates must either be Members of the College by Examination of more than five years standing, or
Members who have been granted exemption from Examination.

b. The Fellowship is ordinarily awarded to a Member for unusual distinction in teaching, research, and/or administrative ability, or for exceptional service to patients, especially where the supporting services have been inadequate. Sponsors are therefore asked to indicate any factors which go beyond the carrying out of consultant or academic duties by the candidates of their choice.

All sponsors and all successful candidates will be notified by letter of the decision of the Court of Electors.

Individuals elected to the Fellowship become entitled to use the designation FRCPsych after they have paid the prescribed registration fee.

\section{The Missing Examination Papers}

Examiners and examinees have nightmares of things that can go wrong in examinations. Last February, one of them came true.

A batch of eight Preliminary Test essay papers was lost by the Post Office. They were amongst all the others posted at the same time, by recorded delivery. Extensive searches were of no avail. Two decisions had to be made. First, how to examine the eight candidates, and secondly to review the College's postal procedures.

We decided that the fairest procedure would be to set a new essay paper for the candidates, at least for those whose MCQ marks still left them in the field. This was arranged in May, and the essay scripts were rushed to the Examiners who would have marked those which were lost.
Clearly it is the College's responsibility to decide how essay papers should be handled. Hitherto, in its 15 years of experience, none have been lost. A good record, but of course it should be impeccable. We checked with other Colleges, and discovered that there had been the odd loss from ordinary post, datapost, and registered post. On the basis of our own experience, and our enquiries, and after much thought, we have decided not to change our present system. The alternative-a courier service-might have marginally less risk, but it would add, considerably to the cost of the examination.

J. L. T. BIRLEY, Dean

\section{Pass List}

The Examinations Sub-Committee has decided that from October 1986 a pass list of successful candidates in the Preliminary Test and the Membership Examination should be sent out to Academic Departments of Psychiatry in the
United Kingdom and the Republic of Ireland one week after the results are released to candidates.

Heads of Department have been asked to pin the list on Notice Boards for approximately one week. 